\title{
On the Stylistic Features of Legal English
}

\author{
Zhansheng Feng \\ Foreign Languages Department, Zhengzhou University of Light Industry \\ 5 Dongfeng Road, Jinshui District, Zhengzhou City, Henan Province, 450002, China \\ Tel: 86-371-6355-6322Ｅ-mail: fdpyxx@126.com
}

Received: March 9, 2012

Accepted: March 29, 2012

Published: June 15, 2012

doi:10.5430/wjel.v2n2p29

URL: http://dx.doi.org/10.5430/wjel.v2n2p29

\begin{abstract}
At present, most of places are ruled by law, and legal affairs in these places are more and more internationalized. In addition, English is the international language, which is the most popular. Therefore, it is important and necessary for us to have a discussion on the stylistic features of legal English in order to help relevant practitioners and scholars to deal with legal texts in English. Legal English has its own stylistic feature on different levels including graphological level, lexical level, and syntactic level. On graphological level, legal English takes on the features including the same capitalization, the same font style, the same font size, etc. in the same kind of legal documents; on lexical level, it takes on some features including archaisms, loan words from Latin and French, technical terms; on syntactic level it takes on some features including declarative sentences, long and complex sentences, complete sentences. Although all of stylistic features are not dealt with, these main features are important for relevant persons to deal with legal texts.
\end{abstract}

Keywords: Stylistic features, Legal English, Graphological level, Lexical level, Syntactic level

\section{Introduction}

Today, most of places on the earth are ruled by law. Without no exception, all of these laws exist with the appearance of languages of statutes or cases. And according to a philosopher with the name David Hume (1739), law and law system are purely one of linguistic forms. Furthermore, John McGowan (2007) says that David Hume(1739) also holds that the rule of law can be most fully thought through one of linguistic tools. Obviously, language is very important for all kinds of laws and relevant rules, and therefore, it is necessary for us to study legal language. David, G.(1997) points that Among all kinds of languages existing in today's world, English, exactly saying, modern English is the first global lingua franca. In fact, it is the dominant language and on some occasions it is often regarded as the required international language of communications in the course of some legal practices or academic activities. Besides, there exist many unique features of English appearing in the course of legal study and practice. In such a case must be carried out a study on legal English especially from the angle of interdisciplinary thoughts.

In fact, there lies a long history of study on legal English, which, in some experts' opinions, is not so long and not very rich in academic achievements. The famous English scholar with the name Hobbes(1660), in his celebrated works Leviathan, points out that law and other rules must be clearly expressed by language, and legal language, with the nature explicity, plays an important role in legal operation, which is the first time to study on legal language mainly referring to legal English. And in 1823, Jeremy Bentham, a famous jurist, also wondered about the importance of studying legal language in his famous works An Introduction to the Principle of Morals and Legislation. Later, George Coode, a barrister and poor law reformer, who also served as an assistant secretary to the Poor Law Commission, composed a book On legislative expression: the language of the written law in 1843, which, in the scientific sense, embarks on the Anglo-American study on legal language. From the middle of the $19^{\text {th }}$ century to the beginning of the $20^{\text {th }}$ century, Anglo-American scholars mainly including John Austin, Julius Stone, Thomas Erskine Holland, William Markby, etc., who study legal positivism, also called analytical positivism by some experts, actually solve problems through means of legal language. Since the middle of last century has been going on a new-analytic movement, in the course of which scholars take advantage of the $20^{\text {th }}$ century's linguistic achievements to solve all kinds of jurisprudential problems. In such a case, these experts in law probe into legal language especially legal English at first, and then they wonder about relevant problems from the angle of linguistic view. One of representatives of such a kind of scholars is Ronald M. Dworkin (1992), one part of whose works Law's Empire deals with the importance of legal language in the course of the study on the science of law. The above are academic achievements of the jurisprudential field and their prominent 
characteristic are only from the angle of the need of the study on the science of law, but not from the linguistic angle.

There is relatively a short history of linguists or linguistic experts to embark on the study on the legal language, especially legal English. The first concerning monograph that the author has found is ENGLISH IN THE LAW COURTS published by Margaret M. Bryant through Columbia University Press in 1930, which mainly deals with the usage of articles, prepositions, and conjunctions play in legal decisions. And it is David Mellinkoff who firstly systematically studies legal English in his treatise THE LANGUAGE OF LAW published in Little, Brown and Company of Boston in 1963. Later more and more linguists participate in legal language, and they achieve a lot and develop a set of their own studying method. On such a basis, there appear one magazine with the name The International Journal of Speech, Language and the Law and two concerning international organizations, which are International Association for Forensic Phonetics and Acoustics (AFPA) and International Association of Forensic Linguistics (IAFL). These two organization and the magazine are the hallmarks of the discipline's coming into being. Before the appearance of the both organization, achievements of legal language scattered in relevant articles, treatises except O'Barr's study of legal language. After 2000, there appear longer attainments - monographs, in some of which there are words of "legal language". And these attainments mainly centers on legal language, (Solan and Tiersma 2005; Tiersma 1999), speech interaction in the courtroom (Archer 2005; Heffer 2005; Matoesian 2001, 2003; Solan 1993; Stygall 1994), speech and power (Conley and O'Barr 1998; Cotterill 2003), and they mainly deal with legal speech in forensic activities. The latest achievement caught by the author of this thesis is An Introduction to Forensic Linguistics: Language in Evidence composed by Malcolm Coulthard and Alison Johnson, which was published in Routledge in 2007.

Among the above attainments in the study of legal language, there are some about special studies on the style of legal English. As mentioned above, George Coode, though not a linguist, probed into legislative expression of legal English in the written law from the angle of legislative practice, and Margaret M. Bryant studied on form-words existing in English in the courts, which is also one branch of legal English. And David Mellinkoff had, firstly, the systematical study on legal English. Later, there are more and more scholars studying legal English, most of them are only language experts. In practical fields have even appeared professional services of writing, translation, and interpretation of legal English. But it is regretful that most of these scholars and professionals studying or dealing with legal English only from one single angle of law science or linguistic science, but not from the angle of interdisciplinary science. So it is necessary for us to have an interdisciplinary study on legal English, especially on its stylistic features.

Of course, it is valuable to study the stylistic features of legal English. Firstly, with the globalization of all kinds of affairs, especially legal affairs, international society needs a communication tool. Because English is the most popular language, and most of places in the world are ruled by law, the study on legal English can contribute to people's knowledge of legal English, which can improve conveniences of communication on international occasions of legal affairs. And studying such this topic can acquaint college students in law school with this special kind of language, which often appears in their reading materials. Besides, this study can invoke legal professionals to improve their competent on legal occasions above mentioned.

\section{The Stylistic Features of Legal English and Interdisciplinary Examination}

As one of professional style of English, legal English is often used by judges, lawyers, public procurators, relevant scholars, and other professionals in their work. Since Martin Joos presents five styles of language such as the intimate style, the consultative style, the casual style, the formal style and the frozen style, legal English should belong to part of the frozen style although it is also one of the most formal one among various English varieties. In order to make our study convenient, here we will wonder about the unique stylistic feature from graphology, lexical, syntactic and discourse levels on the interdisciplinary view.

\subsection{Features on Graphological Level}

On this level, the legal English appears with stylistic features such as the same capitalization, the same font style, the same font size, etc. in the same kind of legal documents. For example, in the Constitution of the United States repeatedly appear such phrases "We the People of the United States", "in Order to form a more perfect Union", "establish Justice", "insure domestic Tranquility", etc. Here, all of these expressions, with some Capitals, mainly personifies, or dignifies some lexicon item. Besides, legal English is featured by initial capitals in key words of some legal documents in English. In the English version of legal documents of the People's Republic of China, rules of the unified fonts and forms are laid down by relevant organs of state power such as National People's Congress, State Council, Central Military Commission, Supreme People's Court, Supreme People's Procuratorate, etc. Even some concerning presses also formulate some standards for English in legal documents of People's Republic of China in order to improve their authoritativeness of publishing legal documents. 
In the view of philosophy of law, this feature of legal English is closely related with the nature of law. As a unique phenomenon existing in humankind's social-political activities, law surely has its own natures corresponding with the fact that law is a normative social practice. As law's expression, legal English must exist in the normative form of speech or writing. Therefore, in legal English, there exist the same capitalization, the same font style, the same font size, etc. in order to guide human behavior, presenting reasons for action with authoritativeness. On one hand, law is the tool for state organs to perform their duties since law is the speaker of state power or public order. On the other hand, law must be full of reasons, which can convince citizens to obey laws.

\subsection{Features on Lexical Level}

In addition to the above features on the graphological level, legal English shows a variety of features on lexical level, which mainly refer to archaisms, technical terms, loaning words from other languages, and using synonyms, etc.

\subsubsection{Archaisms}

One of the most remarkable features of legal English is the use of archaic words, which mainly refers to frequent use of old words including Old English words and Middle English words in legal English--a highly regular written language. This feature actually indicates that legal English is conservative, solemn, regular, authoritative and rigid. Here, Old English or Anglo-Saxon, which is a West Germanic language and is closely related to Old Frisian, is an early form of the English spoken and written by the Anglo-Saxons and their descendants. And Middle English, which existed roughly during the period between the late 11th and the late 15th century, is the English language current in England on the stage of the High and Late Middle Ages. It is undeniable that modern English especially today's general English, is influenced by Old English and Modern English. But legal English keeps a large number of Old English words and Middle English words and their meanings, most of which have never been used in Modern English. Compounds adverbs including whereby, thereafter, hereby, henceforth, hereto, etc., the most frequently appear in legal English, and this kind of words are obviously formed by adverbial word and a preposition-like word. Besides above archaic words, David Mellinkoff, the famous linguist, present a fair sampling as follows:

\section{aforesaid and forthwith}

here words: hereafter, herein, hereof, heretofore, herewith

let, as in the law tautology, without let or hindrance

said and such as adjectives

thence and thenceforth

there words: thereabout, thereafter, thereat, thereby, therefor, therefore, therein, thereon, thereto, theretofore, thereupon, therewith

where words, especially whereas used in recitals, and whereby

witness, in the sense of testimony by signature, oath, etc., as in "In witness whereof, I have set my hand, etc."

witnesseth, meaning to furnish formal evidence of something, the old English present indicative third person singular verb form.

Besides the above words, the author has come across such words as pursuant to, thence, whereof, whereon, etc.

The law in countries in which English is official language mainly belongs to Common-Law System, in which Case Law are carried out. Here, case law refers to the set of reported judicial decisions from some courts including selected appellate courts and other courts. And during these decisions, the judge firstly make new interpretations of the law which can be used as precedents in later decisions of similar cases. It is easily seen that precedents play very important, even decisive, roles in the operation of law of Common-Law System. And the system came into being with many precedents in Old English or Middle English because either of them was official language when these precedents appeared. Most of these precedents are used in today's foensic practices, and some of them impose great important influences on today's forenic language, which appears with the feature of archaisms in the vocabulary of today's legal English.

\subsubsection{Loan Words from Latin}

English is a mixed language, and one of this linguistic characters is that this language borrows a large number of words from Latin. As one of varieties of English, legal English also loans many words from Latin, and these words can be divided into three kinds. One kind of them often appear in people's activities involving forensic affairs and have been recognized in our daily lives. Such are this kind of words: affidavit, alias, alibi, bona fide, proviso, habeas corpus, in flagrante delicto, inter alia, per diem, prima facie, quorum, sine die, versus, writ of fieri facias, etc. The second kind of 
Latin words in legal English are seldom used in people's daily activities, and people have no chance of coming across them. These words are ex parte, ex post facto, guardian ad litem, in locum parentis, inter partes, per stirpes, res inter alios, res ipsa loquitur, pari passu, in rem, in pesonnam, ipso facto, verbatim (record), etc. There are also one kind of latin words in legal English, which only exist in historical documents on Anglo-American legal history and are only met by some of relevant scholars.

Lexically, Latin has exerted great influence on English. In English, there is a significant portion of the English wordhoard, which is from Romance and Latinate sources. It is estimated that Latin words of $66 \%-80 \%$ exist in English, and even a large number of them are borrowed directly from Latin. However, Latin influence on English, is mainly lexical in nature, which is confined primarily to word origins in the form of Latin roots. As far as Old English is concerned, the first way of Latin influence is through the Germanic tribes such as the Angles, Saxon and Jutes, who often communicate with the Latin speaking Roman Empire through trade and war. The second way is through Christian missionaries who entered Britain in the $7^{\text {th }}$ century or so, and brought Latin religious terms. As for middle English, some words came from Norman language spoken by the royal court and influenced by Latin. And the Church and academic centers continued using Latin, which was actually going on with lexical borrowing from Latin. As the origin of modern English, English in the English Renaissance directly borrowed words from Latin in the form of Latin classical or medieval form. After Renaissance came Industrial Age, which was the dawn of the age of scientific discovery. This kind of discovery needed new words to depict, and there appeared many borrowing words from Latin in English. Besides, some of Latin word elements are used to coin English words with word components from other languages including English. Actually, people have always been using Latinate words to coin words until today. According to the above mentioned, Latinate words have exactly been borrowed to coin words, and legal English, as one of English styles, is featured with loan words from Latin.

\subsubsection{Loan Words from French}

Besides Latin, there are also a lot of words borrowed from French in legal English. In Pollock and Maitland's work with the name The History of English Law 81(2d ed. 1898) are listed some of this sort of words, which are basic to legal vocabulary:

action, agreement, appeal, arrests, arson, assault, attorneys, battery, bill, claim, condition, constables, contract, counsel, count, court, covenant, crime, damage, debt, declaration, defendant, demand, descent, devise, easement, evidence, execution, felony, goals, grant, guarantee, guardian, heir, indictment, infant, judges, judgment, jurors, justice, justices, larceny, lien, marriage, misdemeanor, money, note, obligation, pardon, parties, partner, payment, plaintiff, pleadings, pledge, police, possession, prisons, property, purchase, reprieve, robbery, sentence, servant, slander, suit, tort, treason, trespass, verdict, etc.

There are many historical, political and legal factors contributing to loan words from French in legal English. In 1066 happened the Norman Conquest, which is a historic hallmark. After this event, British governors including kings became more French than English. Law, as wills of governors', should not be exceptional. On one hand, some laws were brought from France by conquerors and were enacted in the upper class throughout the British territory. On the other hand, conquerors came from France, and surely they mainly spoke French though they didn't prohibit people's speaking English and even English and French were heard together at that time. In this case did English exist together with French in England, and French, as a language of rulers, exerted great influence on general English, which changed and even decided legal English which was only a branch of general English.

Besides these influences French exerted on general English, the judicial system at that time affected legal language, and one aspect of this influence is also that official language in judicial activities borrowed many words from French. Actually, at the beginning of his governance, William didn't oppose English native culture especially including judicial system and even permitted the native culture to develop to some degree. At that time, the local courts originally set by England also were kept and let to administer justice according to ancient law or customs of England. But the King's Court was actually a gathering of King and his courtiers, most of whom were Normans from France. If people was not satisfied with decision made by local court, in which were English-speaker judges who often carried out their local law and costumes, they often appealed to higher courts including the highest court-King's Court. So, forensic activities in England, at that time, were greatly influenced by French, and even final decision was made by French-speakers including King and his courtiers. After Norman Conquest, staffs in judicial organs especially in higher courts in British territory were French and some of them, though not French, are more French, which directly influenced forensic expressions including loan words from French. In British history, it was the French version of William's laws translated from Latin in late twelfth-century that appeared earliest in British territory. This French version is the visible sign that French influenced legal English. After that, French influence on legal English was more and more obvious and serious, and even today this influence also can be traced in legal literature in English. 


\subsubsection{Technical Terms}

There are its own technical words in every profession, which are called technical terms or terms of art actually referring to a group of words with specific meanings to describe concepts in the field of some profession. Technical terms in the field of law refer to terms of legal art, which have their own special connotation and extension in the legal sense. These kinds of words are frequently and massively used to more concisely express complex concepts concerning law and will not be replaced by other glossary. Therefore, they are convenient for lawyers, judges and other legal practitioners to express their ideas in their own forensic practices. Here is a list of this group of terms of art:

agency, alibi, alias summons, amicus curiae, appeal, bail, common counts, comparative negligence, defendant, demurrer, fee simple, fee tail, fictitious defendant, guarantee, habeas corpus, guarantor, judicial notice, laches, landlord, tenant, lessor, lessee, letters patent, master and servant, month-to-month tenancy, negotiable instrument, plaintiff, principal and surety, surrender, tort, voir dire...

As mentioned above, law is a profession of words. Law is a high specialty can firstly be shown through its specific language - legal language, which is because forensic or other activities are very stern and grave and legal or forensic practitioners must be meticulous and precise in their expressions of relevant activities. The sticking characteristic is each technical term has merely one single and fixed meaning. Each term of legal art represents one special legal concept, and it can't be replaced by other words. Besides, it, as one term of legal art, can only be used to express one meaning in the legal field in common sense though it general meanings are various. But some of terms of legal art have more than two meanings, and we must grasp their meanings according to the context in which they appear. One case is that one of such technical terms - negligence, which refers to a different concept when appearing in different context such as criminal case or civil case. Terms of legal art are also featured with their matching terms with opposite meaning. For example, in civil cases, there are a complainant; a plaintiff; a demandant and a defendant; the accused; a respondent (esp in a divorce case). And in criminal cases there exist such group of words as prosecutor, accuser and the accused, defendant, respondent.

According to the above, there exist large quantities of terms of legal art, which have their own features. Why such kinds of words in legal English come into being? One of sources is terms of legal art of Ancient Greece, Ancient Rome and Old English. The culture of Ancient Greece and Ancient Rome is the source of modern Europe, with English culture including legal culture no exception. The second source is terms of legal art in French, which has been mentioned above and here is omitted. Besides, forensic practitioners and relevant scholars have created a lot of technical terms in their practices and academic researches.

At last, legal English is not only featured with the above points on lexical level. Argot, synonyms, formal words, expressions with flexible meaning, etc. are often used in legal English, which are also features of legal English on lexical level. Because of limited length of the paper, these features are not dealt with here.

\subsection{Features on Syntactic Level}

\subsubsection{Declarative Sentences}

There are four kinds of sentences including declarative sentences, imperative sentences, interrogative sentences, and exclamatory in general English from the view of syntax. Law is often used to make definite people's interrelationship, and legal documents are often applied to declare such relationships in a general case or in a special case. And legal language in these legal texts must be precise, well-conceived, objective, and standardized so that people can do their own deeds in the legal sense according to law and other relevant legal rules. Therefore, there mainly exist a lot of declarative sentences other than imperative sentences, interrogative sentences, and exclamatory in legal English. For example,

"No person shall be elected to the office of the President more than twice, and no person who has held the office of President, or acted as President, for more than two years of a term to which some other person was elected President shall be elected to the office of the President more than once. But this Article shall not apply to any person holding the office of President, when this Article was proposed by the Congress, and shall not prevent any person who may be holding the office of President, or acting as President, during the term within which this Article becomes operative from holding the office of President or acting as President during the remainder of such term."

“(a) Whoever unlawfully seizes, confines, inveigles, decoys, kidnaps, abducts, or carries away and holds for ransom or reward or otherwise any person, except in the case of a minor by the parent thereof, when- (1) ...; (2) ...; (3) ...; (4) ...; (5) ...; (b) With respect to subsection (a)(1), above, the failure to release the victim within 
twenty-four hours after he shall have been unlawfully seized, confined, inveigled, decoyed, kidnapped, abducted, or carried away shall create a rebuttable presumption that such person has been transported in interstate or foreign commerce. Notwithstanding the preceding sentence, the fact that the presumption under this section has not yet taken effect does not preclude a Federal investigation of a possible violation of this section before the 24-hour period has ended."

Declarative sentences can make legal expression clear and definite, and they are widely used in legal text, which is also one of features on syntactic level.

\subsubsection{Long and Complex Sentences}

Legal scholar with the name Driedger holds that using long sentences is one of features of written English in legal documents. Because legal texts often need concise and exact expression, long and complex sentences tend to appear in legal documents in English, which is also one of stylistic features on syntactic level. Actually, in legal documents, especially of Common Law System, there are many lines of words in many sentences, some of which are even more than ten lines of words. One of such kinds of examples comes as follows:

"All Powers, Authorities, and Functions which under any Act of the Parliament of Great Britain, or of the Parliament of the United Kingdom of Great Britain and Ireland, or of the Legislature of Upper Canada, Lower Canada, Canada, Nova Scotia, or New Brunswick, are at the Union vested in or exerciseable by the respective Governors or Lieutenant Governors of those Provinces, with the Advice, or with the Advice and Consent, of the respective Executive Councils thereof, or in conjunction with those Councils, or with any Number of Members thereof, or by those Governors or Lieutenant Governors individually, shall, as far as the same continue in existence and capable of being exercised after the Union in relation to the Government of Canada, be vested in and exerciseable by the Governor General with the Advice, or with the Advice and Consent of or in conjunction with the Queen's Privy Council for Canada, or any Member thereof, or by the Governor General individually, as the Case requires, subject nevertheless (except with respect to such as exist under Acts of Parliament of Great Britain or of the Parliament of the United Kingdom of Great Britain and Ireland) to be established or altered by the Parliament of Canada." ${ }^{3}$

The feature of long and complex sentences in legal English depends on the context of legal English, which is one of English for Special Purpose (ESP). Such contexts which involve legal activities and legal environment need many words, phrases or clauses to modify and qualify headwords in order to make legal expression achieve the purposes of communication.

In addition, there are many fixed sentence structures with many special legal meanings in long and complex sentences of legal texts. And meanings of these sentence structures in such contexts differ from them in common contexts excluding legal contexts. Such examples come as...subject to..., provided that/provided...that, where..., for the purpose of..., notwithstanding..., without prejudice to..., to the extent that..., save.../except (for).., etc.

\subsubsection{Complete Sentences}

Because legal texts have their own complete sentence structures and strict meanings, sentences of legal English usually are complete sentences, in which there are subjects and predicates. These complete sentences often express what legal contexts involve, and avoid misunderstanding and ambiguity brought by omission and default of sentences in common sentences. For example,

"He shall have Power, by and with the Advice and Consent of the Senate, to make Treaties, provided two thirds of the Senators present concur; and he shall nominate, and by and with the Advice and Consent of the Senate, shall appoint Ambassadors, other public Ministers and Consuls, Judges of the supreme Court, and all other Officers of the United States, whose Appointments are not herein otherwise provided for, and which shall be established by Law: but the Congress may by Law vest the Appointment of such inferior Officers, as they think proper, in the President alone, in the Courts of Law, or in the Heads of Departments."

In fact, here the second "he" may be omitted in common contexts to avoid ambiguity and misunderstanding. Though this kind of sentences is also long and complex, it, on earth, are a complete sentence, in which subjects, predicates, and even objects, complements and adverbials, in some cases, are not omitted. 


\section{Conclusion}

From the above analysis, the stylistic features of legal English on different levels are easily caught by us. There are features on Graphological Level such as the same capitalization, the same font style, the same font size, etc. in the same kind of legal documents. And on lexical level, such features exist as archaisms, loan words from Latin and French, technical terms. Finally, on syntactic level there are also some features including declarative sentences, long and complex sentences, complete sentences. Of course, here only main stylistic features of legal English are dealt with, and some features not so important as the above are omitted because of limited printed sheets of the journal. And such omissions are expected to be probe into in the future. I believe sure stylistic features listed above must be helpful to legal practitioners, legal scholars, and other relevant persons because legal affairs have become more and more international and their concerning documents are mainly in legal English since English is the most important international language and the most popular language among the world.

\section{References}

Archer, D. (2005) Questions and Answers in the English Courtroom(1640-1740): A sociopragmatic analysis, (p. 56). Amsterdam: John Benjamins.

David, G. (1997) "Global English: gift or curse?” [Online] Available:

http://journals.cambridge.org/action/displayAbstract;jsessionid=92238D4607726060BCBD3DB70C472D0F.tomcat1?fr omPage $=$ online\&aid=291932. Retrieved 4 April 2005.

David, G. (1997) “The Future of English?” [Online] Available:

http://www.britishcouncil.org/de/learning-elt-future.pdf. Retrieved 15 April 2007.

David, H. (1739) . Treatise of Human Nature.( p.263), London: Longman.

David, M. (1963), The Language of the Law. (p. 13). Boston: Little, Brown and Company.

Driedger, E. (1976), The Composition of Legislation, Legislative Forms and Precedents,2nd. Ed,(p. 23). Ottawa:Department of Justice.

Hobbes. (1660) Leviathan. (p. 36). Oxford: Oxford University Press.

Jeremy, B. (1823), An Introduction to the Principle of Morals and Legislation. (p.432). Oxford: Clarendon Press.

John, M. (2007). American liberalism: an interpretation for our time. (p. 30), Chapel Hill: The University of North Carolina Press.

Ronald, M. (1992), Review of Dworkin's Law's Empire. Faculty Publications-Philosophy. Paper 22.

Solan, L. \& Tiersma, P. (2005), Speaking of Crime: The language of criminal justice, (p. 43). Chicago: University of Chicago Press.

Tiersma, P. (1999) Legal Language. (p. 56). Chicago, IL: University of Chicago Press.

\section{Notes}

Note 1. Amendment 22 of the United States Constitution.

Note 2. United States Code: Title 18, 1201. Kidnapping.

Note 3. Section 12 of the Constitution Act, 1867.

Note 4. Section 2 of the United States Constitution. 